\section{Targeted Drug Therapies for Bladder Microbiota: Myth or Future of Benign Prostatic Hyperplasia Treatment?}

\section{Sir,}

The severity of lower urinary tract symptoms (LUTS), caused by benign prostatic hyperplasia $(\mathrm{BPH})$, can be progressive. A combination therapy with alpha-blockers and 5-alpha-reductase inhibitors is sufficient for most patients. However, in 12.6\% of patients treated with combination therapy, clinical progression is seen and 5\% need surgery. ${ }^{1}$ According to American Urological Association, surgery for $\mathrm{BPH}$ is recommended for patients with LUTS attributed to BPH refractory to other therapies. ${ }^{2}$ Factors, such as unresponsiveness to medical therapy and progression of disease despite medical therapy, suggest that there is still a lack of effective therapy for LUTS, probably due to its heterogeneous and poorly understood underlying pathophysiology.

Bacterial DNA and existence of bladder microbiota in men invalidated an entrenched dogma that urine is sterile. Studies showed that bladder microbiota may play a role in urinary incontinence and response to incontinence treatment. ${ }^{3}$ Recent advancements in the understanding of female urinary microbiota with different bladder diseases lead the investigators to explore similar relationships in the male urinary microbiota. Lewis et al. observed that microbiota in the distal urethra was decreased in numbers and was increased in diversity with age. ${ }^{4}$ These urethral microbiota changes with aging and similar observations revealed that a possible relation between bladdermicrobiota and BPH/LUTS is becoming more realistic.

Researchers have identified different bacteria species in the bladder. Although some lactobacilli species have protective effects against LUTS, the others do not. In BPH patients, many voiding symptoms result from the changes in the bladder. Additional investigations of the bladder microbiota may elucidate associations with the severity of LUTS. Bajic et al. found a positive correlation between IPSS score and the presence of bladder bacteria in men. This finding suggests an existence of a relation between bladder microbiota and LUTS severity in men. ${ }^{5}$ The severity of urinary symptoms increases in men with more detectable bladder bacteria. These findings may open a research field to explore future design of drugs targeting specificmicroorganisms of bladder. Understanding the relationship between LUTS symptoms and bladder microbiota may improve BPH related symptoms management. This scientific progression would be beneficial for patients and also reduce costs of long lasting medical therapies and inpatient hospitalisations for BPH surgery.

In future, surgical procedures for BPH treatment are likely to decrease with the development of individualised targeted drug therapies for bladder microbiota and their products.

\section{CONFLICT OF INTEREST}

None to declare.

\section{AUTHOR'S CONTRIBUTION:}

TA: Conception and design of the work, and drafting the manuscript.

\section{REFERENCES}

1. Roehrborn CG, Siami P, Barkin J, Damião R, Major-Walker K, Nandy I, et al. The effects of combination therapy with dutasteride and tamsulosin on clinical outcomes in men with symptomatic benign prostatic hyperplasia: 4-year results from the CombAT study. Eur Urol 2010; 57(1): 123-31. doi: 10.1016/j.eururo.2009.09.035.

2. Foster HE, Barry MJ, Dahm P, Lerner LB, Parsons JK, Wilt TJ, et al. Surgical management of lower urinary tract symptoms attributed to benign prostatic hyperplasia: AUA guideline amendment. J Urol 2019; 202(3):592-8. doi: 10.1097/JU.0000000000000319.

3. Thomas-White KJ, Hilt EE, Fok C, Pearce MM, Mueller ER, Kliethermes $S$, et al. Incontinence medication response relates to the female urinary microbiota. Int Urogynecol J 2016; 27(5):723-33. doi: 10.1007/s00192-015-2847-x.

4. Lewis DA, Brown R, Williams J, White P, Jacobson SK, Marchesi JR et al. The human urinary microbiome; bacterial DNA in voided urine of asymptomatic adults. Front Cell Infect Microbiol 2013; 3:41. doi: 10.3389/fcimb.2013. 00041.

5. Bajic P, Kuiken MEV, Burge BK, Kirshenbaum EJ, Joyce CJ, Wolfe AJ, et al. Male bladder microbiome relates to lower urinary tract symptoms. Eur Urol Focus 2020; 6(2):376-82. doi: 10.1016/j.euf.2018.08.001.

Turgay Akgul

Department of Urology, Medical Sciences University, Ankara Training and Research Hospital, Turkey

Correspondence to: Dr. Turgay Akgul, Department of Urology, Medical Sciences University, Ankara Training and Research Hospital, Turkey

E-mail: turgayakgul@gmail.com

Received: March 31, 2020; Revised: April 01, 2020;

Accepted: April 02, 2020

DOI: https://doi.org/10.29271/jcpsp.2021.04.492 